\title{
A Late Palaeolithic assemblage at Kunjaram, south-east India
}

\author{
Malavika Chatterjee ${ }^{1}$,Kumar Akhilesh ${ }^{2}$, Shanti Pappu ${ }^{2, *}$, \\ Sudha Ravindranath ${ }^{3} \&$ Udayaraj $^{4}$
}

\section{Introduction}

In contrast to the Acheulian and Middle Palaeolithic, the Late Palaeolithic archaeological record of the south-east coast of India is poorly understood (Pappu 2001; Petraglia et al. 2010; Pappu et al. 2011). Considerable uncertainty surrounds the definition of the bladebased microlithic or non-Levallois, flake-based assemblages, largely as a result of the lack of chronometric dates from excavated sites and due to the paucity of lithic studies (Pappu 2001). The Late Palaeolithic is a crucial period in relation to questions about the dispersals of anatomically modern humans across India and Sri Lanka (Petraglia et al. 2010; Mellars et al. 2013; Roberts et al. 2015) and regional evolutionary trajectories of blade technologies. Here, we present an overview of the site complex of Kunjaram (KJ) in the Kortallaiyar River Basin, Tamil Nadu, south-east India. This represents one of the 43 Late Palaeolithic sites documented in this region (Pappu et al. 2010). While analysis of the lithics from other sites continues, we focus here on the lithic assemblage from KJ-3 because of its good preservation and potential to yield information on all stages of the reduction sequence, as well as its geographic proximity to the Lower and Middle Palaeolithic site of Attirampakkam, which would enable the construction of regional cultural sequences.

The Kunjaram complex comprises three distinct localities with extensive artefact spreads: $\mathrm{KJ}-1, \mathrm{KJ}-2$ and KJ-3 - the latter forming the focus of this study (Figure 1). The site has been sporadically investigated and was previously categorised as 'post-Middle Palaeolithic' (Pappu 2001). To the west of the site lie the Allikulli Hills, running north-north-east to south-south-west and rising to $200-380 \mathrm{~m}$ asl, as well as comprising a Cretaceous boulderconglomerate, rich in quartzite clasts. This constitutes the principal source of raw lithic material used regionally from the Acheulian onwards. Kunjaram is located on a pedimenta gently sloping bedrock surface, extending eastwards from the Allikulli hill ranges-with artefacts lying at elevations of $45-59 \mathrm{~m}$ asl, occurring in the context of ferricrete gravels (Pappu et al. 2011).

\footnotetext{
Department of Archaeology, Deccan College, Pune 411006, India

Sharma Centre for Heritage Education, 28 I Main Road, C.I.T. Colony, Mylapore, Chennai 600004, India Regional Remote Sensing Centre—South, (RRSC-S) NRSC, ISRO, Department of Space/Government of India, ISITE Campus, Marathahalli, Outer Ring Road, Bangalore 560 037, India

4 National Remote Sensing Centre, ISRO, Deptartment of Space, Balanagar, Hyderabad 500 037, Telangana, India

* Author for correspondence (Email: pappu.shanti@gmail.com)
}

(C) Antiquity Publications Ltd, 2017 ANTIQUITY 91360 , e2 (2017): 1-6 


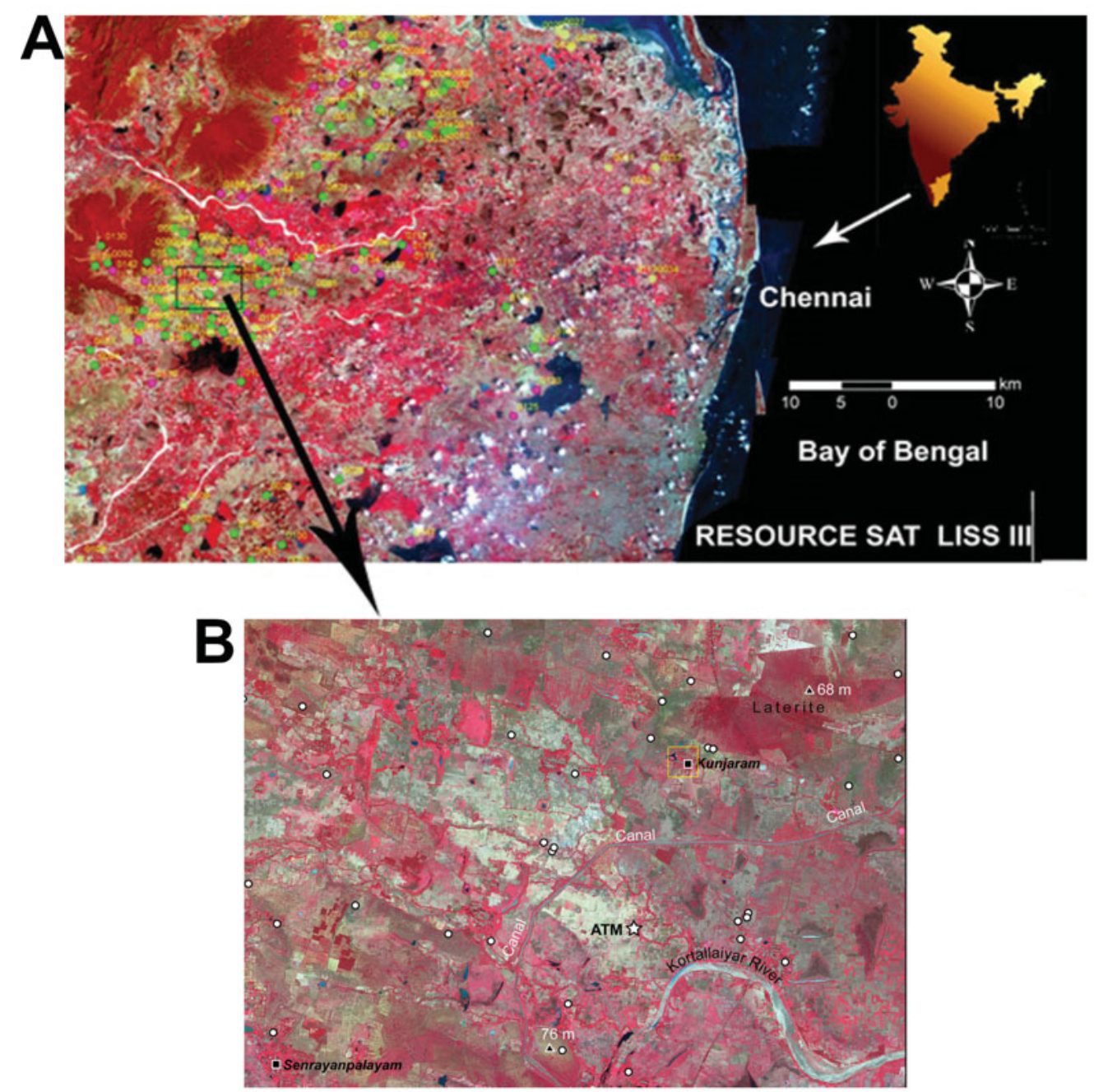

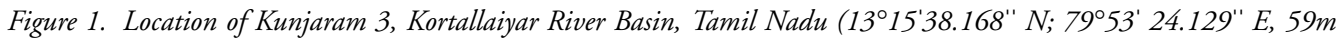
asl), showing A) the general view of the region located in northern Tamil Nadu, south India; and B) IKONOS satellite image of the area under investigation, with white circles indicating prehistoric sites, and the yellow box indicating the Kunjaram site-complex. ATM indicates the Palaeolithic site of Attirampakkam, which is located in the vicinity.

\section{Stratigraphy}

The KJ-3 artefacts rest on the surface of, and are eroding from, the upper levels of ferricrete gravels overlying shales attributed to the Sriperumbudur Formation. Elsewhere in the vicinity, the Kunjaram-complex artefacts overlie ferricretes with Middle Palaeolithic artefacts, which in turn rest on a ferricrete profile developing on shales. The ferricrete gravels are capped by rubified sands located in the vicinity that were dated to $\sim 9$ ka at KJ-1 (Pappu et al. 2009) (Figure 2).

(C) Antiquity Publications Ltd, 2017 


\section{Lithic assemblage}

Artefacts extend over the pediment surface, with a density exceeding $\sim 4-5$ artefacts $/ \mathrm{m}^{2}$. The KJ-3 artefacts studied $(n=522)$ are a sample of the total collected from the site (Pappu et al. 2010). Fine- to medium-

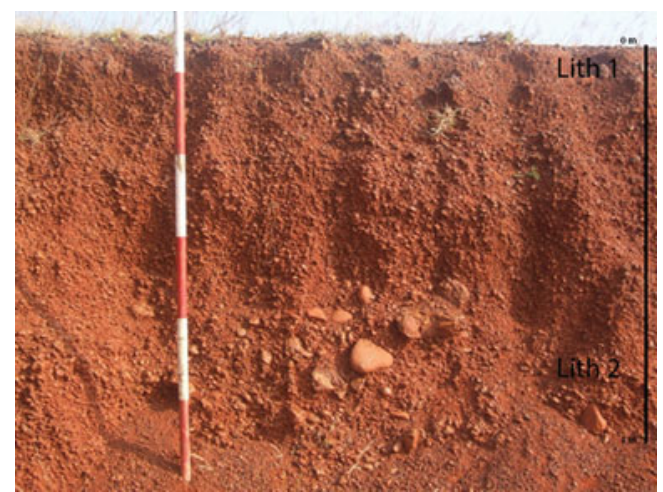

Figure 2. Stratigraphic sequence showing lithological unit1: ferricrete gravels containing Late Palaeolithic artefacts; lithological unit-2: ferricretes containing Middle Palaeolithic artefacts. grained quartzites were preferred $(\mathrm{n}=$ 507, 97.13 per cent), sources for which occur off-site within a radius of $\sim 4 \mathrm{~km}$ (Pappu 2001). Nodules of quartz and chalcedony occurring on-site were also used. Of the 41 cores, single-, double-, opposed- and multiple-platform blade cores $(\mathrm{n}=26$; mean dimensions of 36.87 $\times 31.06 \times 19.22 \mathrm{~mm})$ slightly exceed those for flake production. Platform and blade-core-rejuvenation flakes $(\mathrm{n}=9)$ also occur. Of the sample of 43 blades (mean dimensions of $27.93 \times 15.33 \times 7.7 \mathrm{~mm}$ ), only 10 were retouched into tools. A high

percentage of blades are broken $(79.06$ per cent), ending in step termination. Single- and multiple-platform flake cores are present. Most tools are on flake blanks $(\mathrm{n}=99,81.1$ per cent), which may be derived both from blade and flake reduction. Tools include a range of scrapers and borers, amongst other types (Figures 3-4). Most artefacts are broken (68.77 per cent), with numerous step terminations. Experimental knapping with a hard stone hammer indicates that breakage patterns reflect knapping errors in blade production (Figure 5). High proportions of waste (64.56 per cent) indicate on-site core reduction.

\section{Conclusion}

The KJ-3 assemblage, although dominated by flakes, has a distinct blade technology. The regional preference for blade technology is rooted in the preceding Middle Palaeolithic, although technological trajectories are as yet unclear (Pappu 2001). Blade-breakage patterns are, in general, indicative of knapping errors. Regional mobility strategies and planning are reflected in the transport of quartzite to the site for further reduction, and in the removal of blades/blade tools from the site (research into the transport of these tools to other local sites is ongoing). Reuse of blade-rejuvenation flakes and extensive core-reduction suggests raw material conservation. The KJ-3 site illustrates strategies that differ from the preceding Middle Palaeolithic, particularly with the absence of Levallois reduction strategies and with the presence of a significant blade component. It also lacks microblade technologies, standardised blade-reduction sequences and microlithic assemblages dated to $\sim 38-48 \mathrm{ka}$ in other parts of India and Sri Lanka (Mishra et al. 2013; Roberts et al. 2015). This site adds new dimensions to the study of the Late Pleistocene in India, demonstrating variability in 


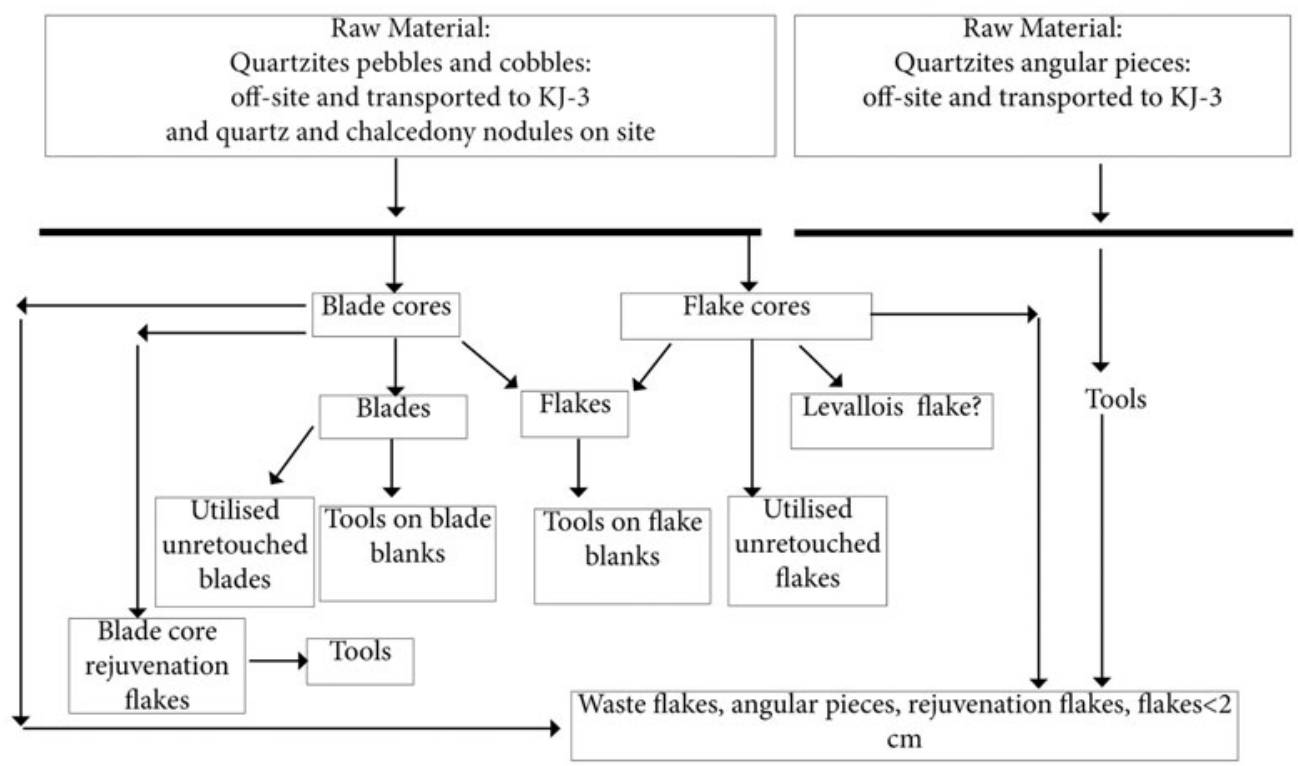

Figure 3. Simplified schematic lithic reduction sequence at Kunjaram 3.

A
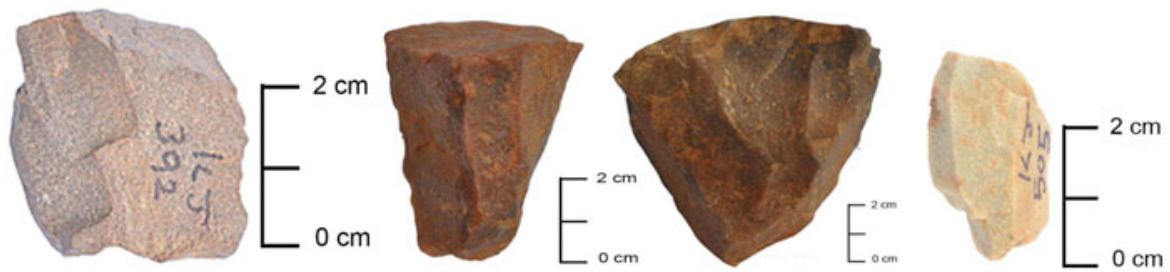
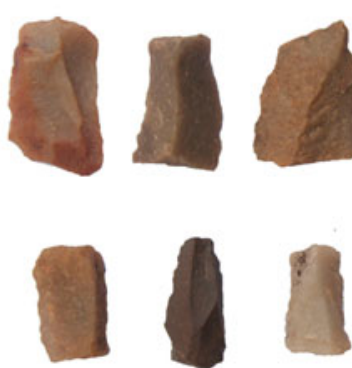
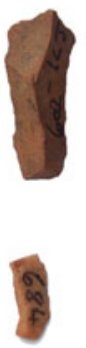

C

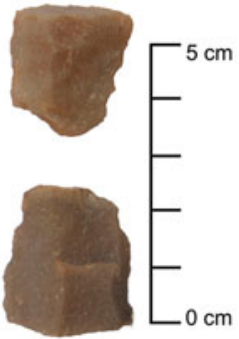

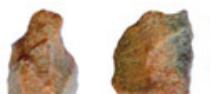
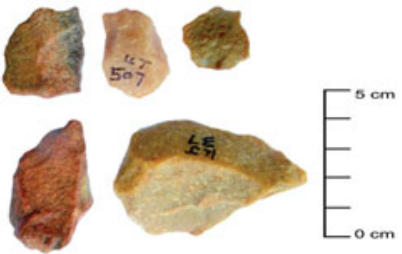

Figure 4. Artefacts from Kunjaram 3: A) blade cores; B) scrapers on blades; C) borers on flakes.

(C) Antiquity Publications Ltd, 2017 
A

B

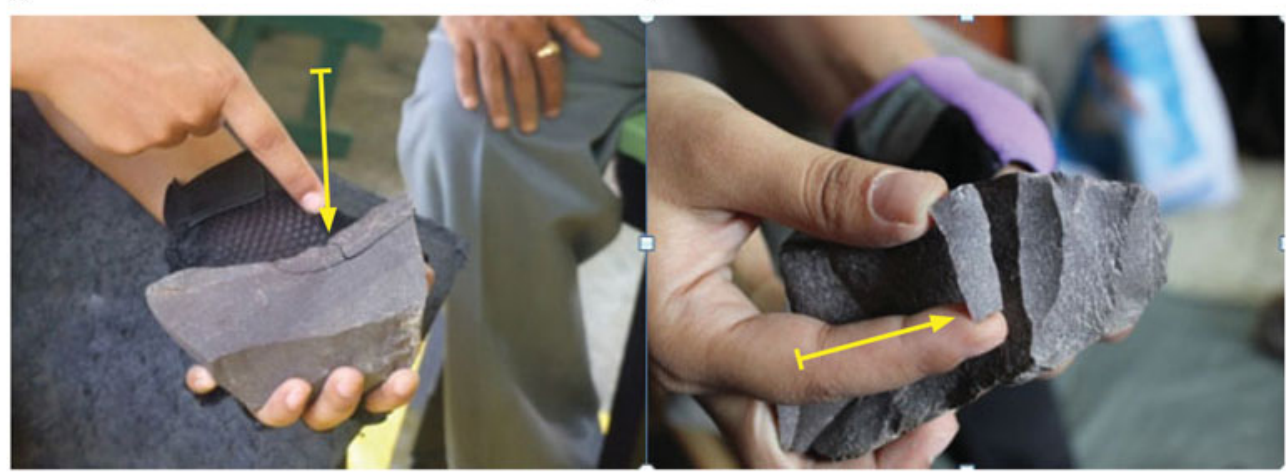

C

$\mathrm{D}$
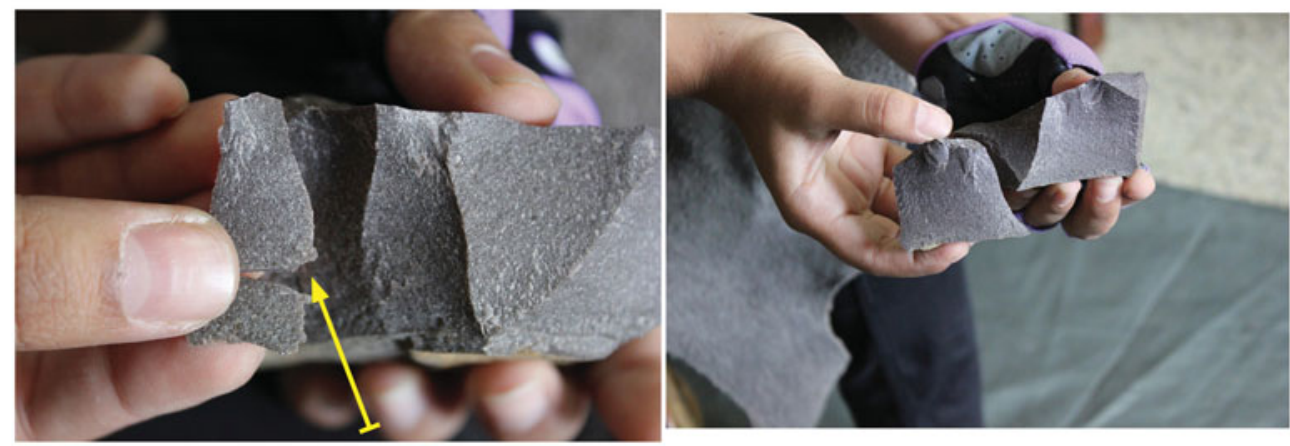

Figure 5. Experimental knapping showing: A) mesial breakage of blades; B) distal breakage of blades; C) breakage of blades towards the distal end; D) flakes produced during blade reduction.

the chronological development and regional distribution of blade technologies across South Asia.

\section{Acknowledgements}

This study is part of M.C.'s MA dissertation at Deccan College, Pune, entitled 'Investigating prehistoric lithic assemblages of Kunjaram, Tamil Nadu' (supervisors: S.P. and K.A). S.P. \& K.A. thank the Indian Space Research Organisation under the ISRO-GBP scheme for the project 'Prehistoric Landscapes in the Palar River Basin, South India'. The Archaeological Survey of India and Department of Archaeology, State Government of Tamil Nadu, granted licences. Data is @Sharma Centre for Heritage Education. K.A. also thanks the Homi Bhabha Fellowships Council (2014-2016).

\section{References}

Mellars, P., K.C. Gori, M. Carr, P.A. Soares \& M.B. Richards. 2013. Genetic and archaeological perspectives on the initial modern human colonization of southern Asia. Proceedings of the National Academy of Sciences of the USA 110: 10699-704.

https://doi.org/10.1073/pnas.1306043110

Mishra, S., N. Chauhan \& A.K. Singhvi. 2013.

Continuity of microblade tehnology in the Indian subcontinent since $45 \mathrm{ka}$ : implications for the dispersal of modern humans. PLoS ONE 8(7): e69280.

https://doi.org/10.1371/journal.pone.0069280 
Pappu, S. 2001. A re-examination of the Palaeolithic archaeological record of northern Tamil Nadu, south India (British Archaeological Reports International series S1003). Oxford: Archaeopress.

Pappu, S., D.P. Shinde, K. Akhilesh, Y. Gunnell, G. Ganbavale, S. Ravindranath, U. Raj \& A.K. Singhvi. 2009. Luminescence dating of prehistoric archaeological sites and Quaternary fluvial and Aeolian deposits in northern Tamil Nadu, south India. Paper presented at the Second Asia-Pacific Conference on Luminescence and Electron Spin Resonance Dating, Physical Research Laboratory, Ahmedabad, India, November 12-15, 2009.

Pappu, S., K. Akhilesh, S. Ravindranath \& U. RaJ. 2010. Applications of satellite remote sensing for research and heritage management in Indian prehistory. Journal of Archaeological Science 37: 2316-31.

https://doi.org/10.1016/j.jas.2010.04.005
Pappu, S., Y. Gunnell, K. Akhilesh, R. Braucher, M. Taieb, F. Demory \& N. Thouveny. 2011. Early Pleistocene presence of Acheulian hominins in south India. Science 331: 1596-99. https://doi.org/10.1126/science.1200183

Petraglia, M.D., M. Haslam, D. Fuller, N. Boivin \& C. Clarkson. 2010. Out of Africa: new hypotheses and evidence for the dispersal of Homo sapiens along the Indian Ocean rim. Annals of Human Biology 37: 288-311. https://doi.org/10.3109/03014461003639249

Roberts, P., N. Perera, O. Wedage, S. Deraniyagala, J. Perera, S. Eregama, A. Gledhill, M.D. Petraglia \& J.A. Lee-Thorp. 2015. Direct evidence for human reliance on rainforest resources in Late Pleistocene Sri Lanka. Science 347: 1246-49. https://doi.org/10.1126/science.aaa1230 